Document downloaded from:

http://hdl.handle.net/10251/101463

This paper must be cited as:

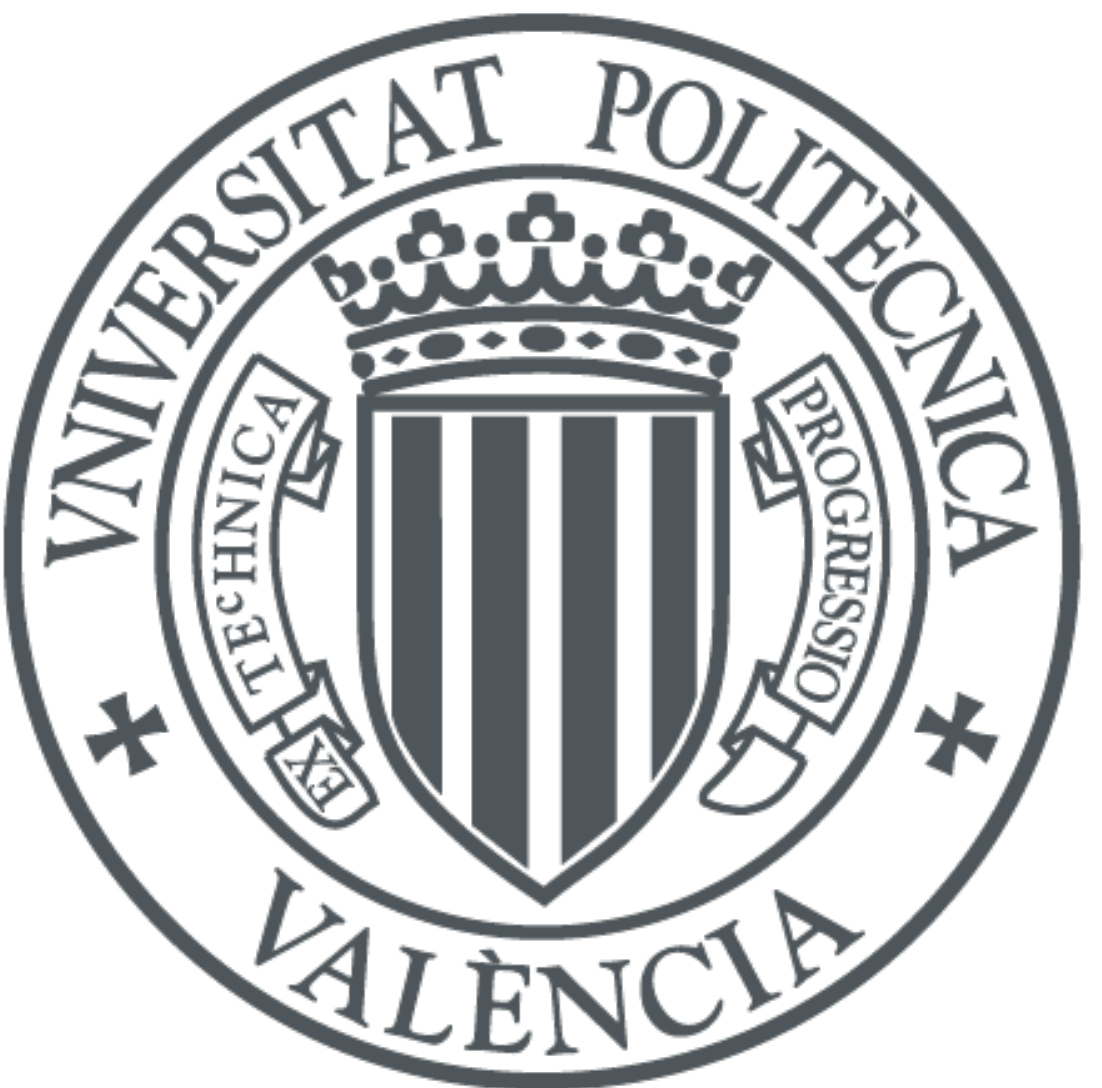

The final publication is available at

http://doi.org/10.1021/ja0603599

Copyright American Chemical Society

Additional Information 


\title{
Rational Design and HT Techniques Allow the Synthesis of New IWR Zeolite Polymorphs
}

\author{
Angel Cantín, Avelino Corma, ${ }^{*}$ Maria J. Diaz-Cabanas, ${ }^{*}$ Jose L. Jordá and Manuel Moliner \\ Instituto de Tecnología Química (UPV-CSIC), Universidad Politécnica de Valencia, Avda. de los Naranjos s/n, \\ 46022 Valencia, Spain,
}

RECEIVED DATE (automatically inserted by publisher); acorma@itq.upv.es

Zeolites are extensively used for adsorption and transformation of organic molecules. ${ }^{1,2}$ Recently, new applications have been developed for electronics, magnetism and medicine. ${ }^{3-5}$ Although more than 160 different structures have been obtained, very few of them are formed by channel systems of different dimensions. However, the presence of connected or unconnected 10 and 12 ring channels in the same structure confers to the zeolite unique catalytic properties for processes such as xylene isomerization, dealkylation and transalkylation of heavy reformate, catalytic cracking and alkylation of aromatics. ${ }^{7-10}$

The first zeolite with interconnected 10 and 12 ring pores was the CON family, formed by SSZ-26, ${ }^{11,12}$ SSZ-33 and CIT- $1 .{ }^{13}$ In a structural study, ${ }^{14}$ it was predicted that besides the observed $\mathrm{A}$ and B polymorphs, a third polymorph $\mathrm{C}$ could exist, that presents double four ring (D4R) units in its structure. More recently, it was found that the introduction of $\mathrm{Ge}$ in the synthesis directs towards new structures in $\mathrm{F}^{-}$and in $\mathrm{OH}^{-}$media, all of them with D4Rs. ${ }^{15-19}$

Thus, since Ge could direct the synthesis towards structures with D4Rs, it was possible to synthesize polymorph C of the CON family (ITQ-24) as a germanosilicate in $\mathrm{OH}^{-}$media. ${ }^{20}$ However, from an industrial point of view, it would be more interesting to produce the corresponding aluminosilicate polymorphs with surface acidity, higher hydrothermal stability, and lower cost than germinates, as well as the pure silica ITQ-24 structure. Excellent papers have been published on fundamentals of zeolite synthesis, ${ }^{21-23}$ and on these bases we have decided to extend them and to achieve Ge free materials containing D4Rs, whit a wide range of Si to $\mathrm{T}^{\mathrm{III}}$ ratios, by combining rationalization with high throughput synthesis techniques. We will show here how this methodology has allowed us to synthesize the Ge free ITQ-24 within a large range of $\mathrm{Si} / \mathrm{T}^{\mathrm{III}}$ compositions, as well as the pure silica polymorph.. This opens one door to synthesize the germanosilicates reported up to now, as Ge free materials.

We started from the fact that $\mathrm{Si}-\mathrm{O}-\mathrm{Ge}$ angles are larger than $\mathrm{Si}-$ $\mathrm{O}-\mathrm{Si}$ or even $\mathrm{Si}-\mathrm{O}-\mathrm{Al}$, but very close to $\mathrm{Si}-\mathrm{O}-\mathrm{B}$. Thus, from the point of view of the structure, introduction of $B$ instead of $\mathrm{Ge}$ produce small changes except for the fact that the presence of $B$ introduces framework negative charges that have to be compensated by cations. On the other hand, if the synthesis is carried out in $\mathrm{F}^{-}$media to stabilize the D4Rs, ${ }^{24}$ this requires the presence of further positive charges to compensate the $\mathrm{F}^{-}$anions. In other words, a system like this requires a large number of SDAs to template the structure while compensating all the negative charges generated. It is then clear, that for a successful synthesis of the Ge free ITQ-24 with a relatively low Si/B ratio we should not use large and rigid organic cations, but rather smaller flexible ones or, even better, flexible polycationic SDAs. By doing this we have one chance to fill up the pores of ITQ-24 while having enough positive charges to compensate the framework and fluoride negative charges.

A SDA which achieves these requirements is hexamethonium (HM), a small flexible dication with a high charge density. The large void volume of ITQ-24 can enclose 3.5 molecules of HM per unit cell, which gives seven positive charges in total. Since this zeolite has only two D4R units per unit cell, then a maximum of two $\mathrm{F}^{-}$are required to stabilize the D4Rs and this leaves still five positive charges unbalanced. This amount is too high to be compensated by defects in a pure silica structure and ITQ-1325 crystallizes instead of ITQ-24, which has a smaller void volume and requires less HM cations to fill up the pores. Nevertheless, if B could be incorporated in the framework, it will compensate the large number of positive charges from the HM and a Ge free ITQ24 borosilicate may crystallize.

Following that idea a set of experiments were designed using $\mathrm{HM}$ as SDA in F media and varying the $\mathrm{Si} / \mathrm{Ge}$ and $\mathrm{T}^{\mathrm{III}} / \mathrm{T}^{\mathrm{IV}}$ ratio in the synthesis gels. Then, by means of a high throughput synthesis robot designed and constructed in house, ${ }^{26}$ gels with the following molar compositions were automatically prepared and crystallized at $175^{\circ} \mathrm{C}$ for 14 days in static conditions (experimental details are given as supporting information).

(1-x) $\mathrm{SiO}_{2}$ : x GeO $2:$ y $\mathrm{B}_{2} \mathrm{O}_{3}: 0.25 \mathrm{HM}(\mathrm{OH})_{2}: 0.50 \mathrm{NH}_{4} \mathrm{~F}: 3 \mathrm{H}_{2} \mathrm{O}$

The results (in supporting information) show that ITQ-24 can be obtained within wide $\mathrm{Si} / \mathrm{Ge}$ and $\mathrm{B} /(\mathrm{Si}+\mathrm{Ge})$ ratios and, when seeding, Ge free B-ITQ-24 was achieved. B can be exchanged by $\mathrm{Al}$ in ITQ-24 samples, ${ }^{27}$ generating strong acid sites catalytically active and selective for benzene alkylation with propylene and dealkylation-transalkylation of heavy reformate.

The ${ }^{27} \mathrm{Al}$ MAS NMR spectrum of the sample calcined at $853 \mathrm{~K}$ and rehydrated presents (not shown) an intense peak at -55 ppm attributed to framework incorporated $\mathrm{Al}$. This is supported by the infrared spectra in the $\mathrm{OH}$ region, and by stepwise pyridine desorption of the Al-ITQ-24 sample (as supporting information). When comparing the acidity of ITQ-24 obtained by the pyridine adsorption/desorption method with that of other large pore zeolites (see supporting information), it can be seen that ITQ-24 presents strong Bronsted acid sites, comparable to those in SSZ33 and Beta zeolites.

Following the discussion outlined above, synthesis of the pure silica ITQ-24 polymorph should require not only $\mathrm{F}^{-}$to stabilize the D4Rs (since there is no Ge present), but a reduced amount of positive charge inside the pores to avoid excess of structural deffects. This hypothesis would require larger SDA cations with lower charge density than HM. Thus, several OSDA which could, in principle, fulfil the above requirements were tested (see supporting information). All this SDA are quite large and rigid 
dications and could be accommodated within the pores of ITQ-24 structure. However, only SDA III gives ITQ-24, while the others direct to ZSM-12 and/or Beta zeolites in Ge free systems and to ITQ-17 from Ge containing gels.
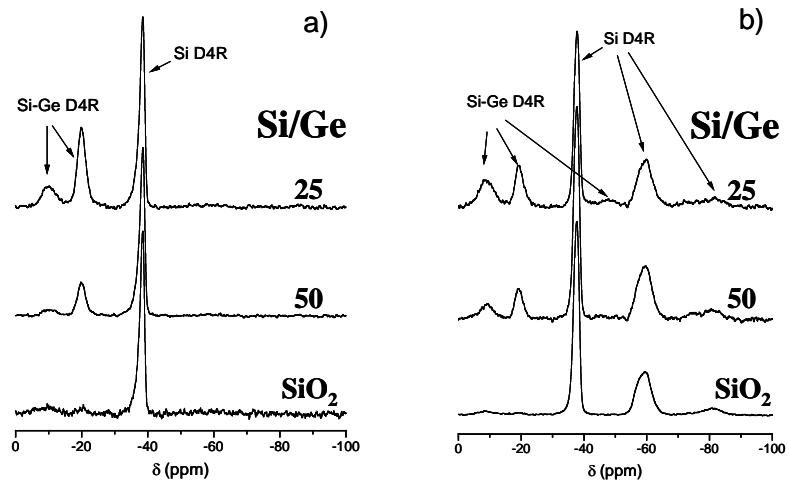

Figure 1. ${ }^{19} \mathrm{~F}$ MAS NMR spectra of the as made ITQ-24 samples. a) BITQ-24 synthesized with HM as SDA. b) Samples obtained with SDA III.

Interestingly, 4,8-(2-methyl)-ethenobenzo[1,2-c:4,5-c'] dipyrrolium-4-methyl-2,2,6,6-tetraethyl-1,2,3,3a,4a,5,6,7,7a,8adecahydro (SDA III) gave ITQ-24 as the only crystalline phase with a $\mathrm{Si} / \mathrm{Ge}$ ratio from 2 to $\infty$ when working in $\mathrm{F}$ media. Working in $\mathrm{OH}$-media ITQ-24 was also crystallized but in a narrower $\mathrm{Si} / \mathrm{Ge}$ range (2-15). Synthesis conditions and materials obtained are included as supporting information.

Ge free ITQ-24 samples were fully characterized. In both cases, the SDA is occluded intact inside the pores. B-ITQ-24 contained $3.5 \mathrm{HM}$ /u.c., while the pure silica contains 2 molecules of the new SDA. The ${ }^{19} \mathrm{~F}$ NMR spectra of the Ge free ITQ-24 samples are shown in Figure 1, together with the low Ge samples (Si/Ge ratios of 25 and 50). In the B-ITQ-24 samples 3 peaks are observed at 8, -20 and $-38 \mathrm{ppm}$, assigned to $\mathrm{F}^{-}$located in the D4R cages with $1 \mathrm{Ge}, 4 \mathrm{Ge}$ and pure silica, respectively, as could be expected since the rest of the charge is compensated by negative charges associated to framework B atoms. In the Ge free sample there is only one peak associated with $\mathrm{F}^{-}$in $\mathrm{D} 4 \mathrm{R}$ at $-38 \mathrm{ppm}$. In the pure silica ITQ-24 sample 3 peaks at -38 , -59 and $-81 \mathrm{ppm}$, are present with a relative intensity of $1.00,0.54$ and 0.09 , respectively. The first peak is assigned to $\mathrm{F}^{-}$in $\mathrm{D} 4 \mathrm{R}$ and the other should correspond to $\mathrm{F}^{-}$in other small cages present in ITQ-24 structure. ${ }^{20}$ In this case, since each SDA has two charges, we can found a maximum of four F per unit cell. As there are 2 D4R/u.c. and considering the relative intensity of the peaks in the NMR spectra, it must be $1 \mathrm{~F}^{-}$probably located in the $\left[4^{2} 5^{4}\right]$ and 0.18 in the $\left[4^{2} 6^{4}\right]$ cages.

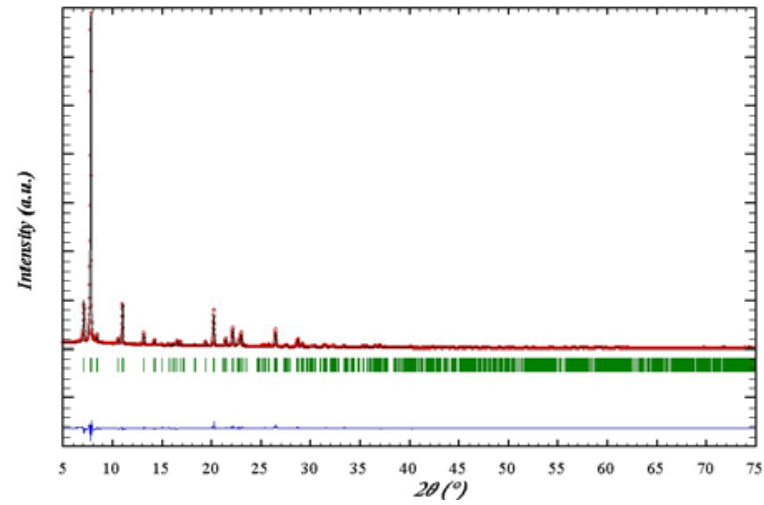

Figure 2. Observed (red) and calculated (black) XRD patterns of calcined pure silica ITQ-24, as well as difference profile (blue). The green short tick marks below the pattern give the positions of the Bragg reflections.
The structure of ITQ-24 was refined in the space group Cmmm with 4 different crystallographic positions for the $\mathrm{T}$ atoms. ${ }^{20}$ Interestingly, the ${ }^{29} \mathrm{Si} \mathrm{NMR}$ spectra of the calcined pure silica ITQ-24 (see supporting information) show at least 5 different positions, indicating that the real symmetry must be lower, although maintaining the proposed topology. The structure was refined using the XRD pattern of the calcined pure silica ITQ-24 sample in the space group Amm2 (No. 38) with the following unit cell parameters: $\mathrm{a}=12.4802(6) \AA, \mathrm{b}=21.0374(10) \AA$ and $\mathrm{c}=$ 13.4698(5) $\AA$. The refined atomic coordinates are given as supporting information, and Figure 2 shows a good agreement between the calculated and the observed XRD patterns ( $\left.R_{w p} 0.12\right)$. The mean distances and T-O-T angles are also included as supporting information.

In conclusion, by combining a rational design of structure directing agents and HT synthesis techniques it has been possible to obtain Ge free ITQ-24 as pure silica as well as borosilicate polymorphs up to a $\mathrm{Si} / \mathrm{T}^{\mathrm{III}}$ ratio of 10 . Al can be exchanged by $\mathrm{B}$ giving strong acid materials. This work opens the possibility to synthesize the $\mathrm{Ge}$ free polymorphs of a large number of new germanosilicate structures reported in the last five years. This certainly will increase their possibilities for industrial application.

Acknowledgment. The authors thank the Spanish CICYT for financial support (MAT2003-07945-C02-01).

Supporting Information Available: Experimental details of synthesis of the SDAs and ITQ-24 samples, crystallographic data, ${ }^{29} \mathrm{Si}$ MAS NMR spectra of calcined silica ITQ-24 and acid properties of Al-ITQ-24 This is available free of charge at (http://pubs.acs.org.

\section{References}

(1) Marcilly, C. Stud. Surf. Sci. Catal. 2001, 135, 37- 60

(2) Corma, A. J. Catal. 2003, 216, 298-312.

(3) Davis, M. E. Nature 2002, 417, 813-821.

(4) Schueth, F.; Schmidt, W. Adv. Engin. Mater. 2002, 4, 269-279.

(5) Scott, B. J.; Wirnsberger, G.; McGehee, M. D.; Chmelka, B. F.; Stucky, G. D. Adv. Mater. 2002, 13, 1231-1234.

(6) Casci, J. L.; Lake, I. J. S.; Maberly, T. R. Eur. Pat. EP378916A1, 1990.

(7) Nacamuli, G. J.; Vogel, R. F.; Zones, S. I. U.S. Patent 5952536, 1999.

(8) Cheng, J. C.; Degnan, T. F.; Beck, J. S.; Huang, Y. Y.; Kalyanaraman, M.; Kowalski, J. A.; Loehr, C. A.; Mazzone, D. N. Stud. Surf. Sci. Catal. 1999, 121, 53-60.

(9) Cheng, J. C.; Smith, C. M.; Weber, W. A.; Brown, S. H.; Steckel, M. A.; Dandekar, A. B.; Better, M. A. PCT WO02/008159, 2002

(10) Serra, J. M.; Guillon, E.; Corma, A. J. Catal. 2004, 227, 459-469.

(11) Lobo, R. F.; Pan, M.; Chan, I.; Li, H. X.; Medrud, R. C.; Zones, S. I.; Crozier, P. A.; Davis, M. E. Science 1993, 262, 1543.

(12) Zones, S. I.; Olmstead, M. M.; Santilli, D. S. J. Am. Chem. Soc. 1992, $114,4195-4201$

(13) Lobo, R. F.; Davis, M. E. J. Am. Chem. Soc. 1995, 117, 3766.

(14) Lobo, R. F.; Pan, M.; Chan, I.; Medrud, R. C.; Zones, S. I.; Crozier, P. A.; Davis, M. E. J. Phys. Chem. 1994, 98, 12040.

(15) Corma, A.; Diaz-Cabanas, M. J.; Rey, F.; Nicolopoulus, S.; Boulahya, K. Chem. Commun. 2004, 12, 1356-1357.

(16) Harbuzaru, B., Paillaud, J.-L., Patarin, J. and Bats, N. Science 2004, 304 990-992.

(17) Corma, A.; Navarro, M. T.; Rey, F.; Rius, J.; Valencia, S. Angew. Chem.,Int. Ed. 2001, 40, 2277.

(18) Corma, A.; Diaz-Cabanas, M. J.; Martinez-Triguero, J.; Rey, F.; Rius, J. Nature 2002, 418, 514-517.

(19) Corma, A.; Rey, F.; Rius, J.; Sabater, M. J.; Valencia, S. Nature 2004, $431,287-290$.

(20) Castaneda, R.; Corma, A.; Fornes, V.; Rey, F.; Rius, J. J. Am. Chem. Soc. 2003, 125, 7820-7821.

(21) Burton, A. W.; Zones, S. I.; Elomari, S. Curr. Opin. Colloid Interface Sci. 2005, 10, 211-219.

(22) Cundy, C. S.; Cox, P. A. Microporous Mesoporous Mater. 2005, 82, 1-78

(23) Sastre, G.; Gale, J. D. Chem. Mater. 2005, 17, 730-740.

(24) Guth, J. P.; Kessler, H.; Caullet, P.; Hazm, J.; Merrouche, A.; Patarin, J. Proc. Int. Zeolite Conf., $9^{\text {th }} 1993,1,215-222$.

(25) Corma, A.; Puche, M.; Rey, F.; Sankar, G.; Teat, S. J. Angew. Chem., Int. Ed. 2003, 42, 1156-1159.

(26) Moliner, M.; Serra, J. M.; Corma, A.; Argente, E.; Valero, S.; Botti, V. Microporous Mesoporous Mater. 2005, 78, 73-81.

(27) Lobo, R. F.; Davis, M. E. Microp. Mater. 1994, 3, 61-9. 


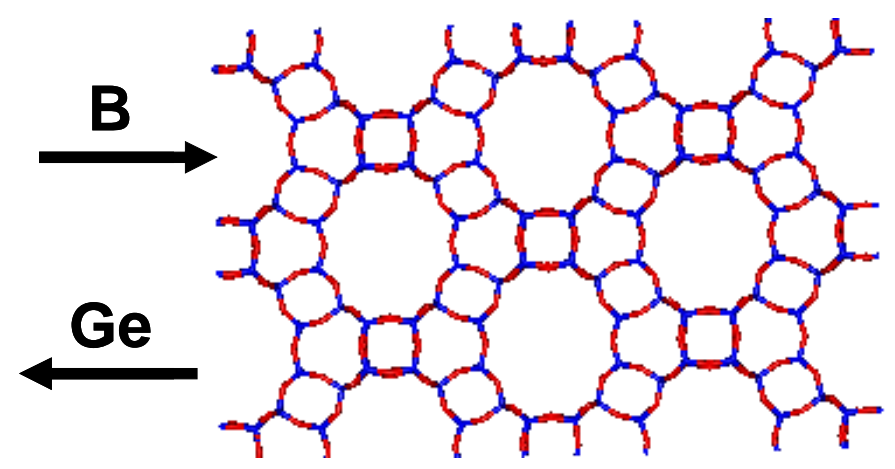

By combining a rational design of structure directing agents and High Throughput and data mining techniques it has been possible to obtain Ge free ITQ-24 as pure silica as well as borosilicate polymorphs up to a Si/TIII ratio of 10 . Al can be exchanged by B giving strong acid materials. This work opens the possibility to synthesize the Ge free polymorphs of a large number of new germanosilicate structures reported in the last five years. This certainly will increase their possibilities for industrial application 